\title{
Political Representation in Liquid Democracy
}

\author{
Chiara Valsangiacomo $0^{1,2,3 *}$ \\ ${ }^{1}$ University of Zurich, Zürich, Switzerland, ${ }^{2}$ Institute of Political Science, Faculty of Arts, University of Zurich, Zürich, Switzerland, \\ ${ }^{3}$ Chair of Political Philosophy, Zürich, Switzerland
}

OPEN ACCESS

Edited by:

Pierre-Etienne Vandamme, Université libre De Bruxelles, Belgium

Reviewed by:

Chiara Destri,

UMR7048, Centre De Recherches Politiques De Sciences Po (CEVIPOF),

France

Valeria Ottonelli,

University of Genoa, Italy

*Correspondence:

Chiara Valsangiacomo chiara.valsangiacomo@uzh.ch

Specialty section: This article was submitted to Elections and Representation,

a section of the journal Frontiers in Political Science

Received: 05 August 2020 Accepted: 15 January 2021 Published: 25 March 2021

Citation: Valsangiacomo C (2021) Political Representation in Liquid Democracy.

Front. Polit. Sci. 3:591853.

doi: 10.3389/fpos.2021.591853
This article provides an in-depth survey of political representation in Liquid Democracy (LD). More precisely, it refutes two potential criticisms: 1) LD impoverishes the concept of political representation relative to existing representative democracies; 2) LD undermines the centrality of political parties. In answer to (1), the article shows that LD is compatible with a selection model of representation, in which proxies are characterized as gyroscopic representatives, driven by intrinsic motivation and indifferent to sanctions. This claim has farreaching normative implications for the mandate-independence tradeoff, anti-elitism, and deliberation under LD. With regard to (2), the article examines the function of parties, arguing that, although it puts parties and interest groups on a level playing field, LD does not threaten partisanship, but rather expands the range of potential carriers of partisanship. In addressing these objections, this article demonstrates the democratic credentials of LD, showing that $\mathrm{LD}$ is compatible with a high-quality, democratic understanding of representation, which is surrounded by a cluster of thick concepts like commitment, intrinsic motivation, alignment of objectives, sympathy, trust, and dialogue. This turns LD into a powerful instrument for the refurbishment of representation both as a unique mode of political participation and as a practice of self-government.

Keywords: political representation, liquid democracy, substantive and gyroscopic representation, selection model of representation, political parties and interest groups, carrier of partisanship

\section{INTRODUCTION}

Liquid Democracy (LD) is a timely, alternative model of collective decision-making that challenges traditional models of electoral representation. LD can be considered a technologically enhanced democratic innovation, containing elements that could help remedy the shortcomings of existing representative-democratic systems, by opening up democracy to citizen participation outside of elections (Landemore, 2020, Ch. 5). The core idea behind LD is that, for each issue to be decided, each citizen has a single vote that can be transferred to a trusted person (or 'proxy') at will (Miller, 1969, 108). In other words, citizens can freely decide whether to cast their vote directly or to delegate it, with a given citizen potentially choosing different proxies for different topics (Blum and Zuber, 2016, $165,168-169)$. Anyone can become a proxy, meaning that the number of 'elected' representatives is potentially unlimited (Tullock, 1967, 145-146). Metadelegation, in turn, allows proxies to transfer their delegations to other proxies, with the caveat that the original voters can withdraw the delegation at any time (Ford, 2002, 4; Green-Armytage, 2015, 199). Significantly, LD uses a weighted-voting system, in which voters who cast their ballot directly have a single vote, while proxies cast all of the votes that have been transferred to them plus their own vote (New York Times, 1912; Alger, 2006). This entire process is facilitated by the use of information and communication technologies. In the present article, I adopt the following working hypothesis: In a population with universal suffrage, LD 
can be used as a voting scheme for governmental policymaking, at the local, regional, and national levels. In other words, LD can be integrated into existing democratic systems, potentially replacing existing electoral processes and reshaping current legislative mechanisms.

That LD is intrinsically concerned with representation is clear from the following concise definition: LD is a decision-making or policy-making scheme based on voluntary delegation and proxy voting, combining aspects of both direct and representative democracy (Valsangiacomo, 2020). On the one hand, LD is direct because citizens enjoy the right to represent themselves and to engage in legislative, issue-specific (German: sachunmittelbar) participation. On the other hand, the representative element in $\mathrm{LD}$ is much more equivocal: For example, can proxies be compared to today's elected members of parliament, or are they a whole new kind of representative? What is their role and what should we expect from them? How does delegation alter the relationship between citizens and representatives? In other words, it is not yet clear how representation in $\mathrm{LD}$ should be conceptualized and how it compares to existing forms of democratic representation. A study of this topic is thus needed, especially since scholars are starting to view $\mathrm{LD}$ as a potential complement to or even substitute for traditional representative democracies (e.g., Blum and Zuber, 2016; Landemore, 2020; Valsangiacomo, 2020).

The aim of this article is thus to conduct an in-depth survey of the concept of political representation in LD, in order to assess its democratic credentials, as well as to identify its role in and value for contemporary democratic theory. To this end, two specific gaps in the literature on representation in LD have been identified, which, if taken seriously, could make LD susceptible to criticism. The first criticism is that $\mathrm{LD}$ impoverishes the concept of political representation in contrast to the virtues associated with representative democracy. To address this objection, more needs to be said about the nature of the proxy-voter relationship, particularly the danger that LD might be reduced to a form of minimalist electoral democracy, in which representation is little more than a transaction scheme of delegations. The second criticism is that LD undermines the central role of political associations (especially parties) due to its focus on proxies and voters qua individuals. In answer to this critique, more needs to be said about political parties and partisanship in LD, particularly the problematic assumption that parties would be superfluous in LD. The article is structured as follows: In Political Representation in Danger, I lay out the groundwork and explain why we should pay attention to political representation in LD. In Of Citizens and Proxies, I address the first gap relating to the voter-proxy relationship. In $O f$ Parties and Partisanship, I examine the problem of political associations. Finally, in Conclusion, I provide a summary of the results, as well as a brief discussion of their relevance.

\section{POLITICAL REPRESENTATION IN DANGER}

LD is intrinsically concerned with representation, but not all forms of political representation are acceptable from a democratic point of view. This section therefore aims to characterize political representation in LD from various angles. It begins by showing that LD inherently fulfills the requirements of the so-called 'formalistic' and 'descriptive' aspects of political representation. ${ }^{1}$ It then provides a brief clarification of what is at stake in discussions of political representation in democracies, which supports my claim that more research is needed to understand how, if at all, representation in $\mathrm{LD}$ can be conceptualized from a more 'substantive' perspective. Finally, this section outlines the two gaps in the research that will be addressed more thoroughly in the following sections.

A clear-cut, analytic, and uncontroversial definition of political representation is absent from the extensive literature on this topic (Rehfeld, 2018, 218-221). For many political theorists of different orientations, representation is the making present (in a non-literal or non-physical sense) by some party of another party, who is absent or otherwise excluded (e.g., Pitkin, 1967, 9; Plotke, 1997, 27; Runciman, 2007; Lacey, 2017, 54; Castiglione and Pollak, 2018, Ch. 1). What distinguishes political representatives from other types of representatives is mainly their acquisition of specific social and political powers (Rehfeld, 2018, 232-235). Because representation is never an end in itself, the nature of these powers will vary depending on how the function of political representation is specified (Rehfeld, 2006, 5-6). The function at issue in this article is collective decisionmaking: Proxies are selected to legislate and their powers thus include sitting in parliament, proposing and discussing policies on behalf of other citizens, and ultimately voting. As long as an eligible citizen has received delegations from other citizens according to the rules of $\mathrm{LD}$, that person must be formally recognized as a representative with all corresponding powers. This nonnormative understanding of representation coincides with the formalistic view of representation outlined by Pitkin (1967), 39; 114: Representation is a mere institutional fact governed by specific rules, which is established at the precise moment of the granting or removal of power. Pitkin distinguishes two main formalistic understandings of representation. On the authorization view, representation results from the concession of one's right to act to somebody else. Elections and sortition are examples of institutions that make such "acts of vesting authority" possible in democracies (Pitkin, 1967, 43). On the accountability view, representation is primarily defined by the accountability of representatives toward constituents. Being subject to reelection and potential removal from office is thus the precondition for elected officials to be representatives (Pitkin, 1967, 56). ${ }^{2}$ Minimalist theories of democracy typically adopt this formalistic understanding, equating democracy with elections (Przeworski, 1999, 12). In LD, proxies are clearly representatives in the formalistic sense, since 1) they are authorized to represent via delegations, and 2) these delegations can be recalled at any time. In other words, the proxies' authority derives from the delegation of voting power, a transaction that

${ }^{1}$ Here I am using Hanna Pitkin's flashbulb metaphor, according to which complex concepts are often multidimensional. In order to reconstruct their meaning, we can approach them from different angles, each of which provides a small piece of the puzzle (Pitkin, 1967, 10-11).

${ }^{2}$ Note that this debate tends to conflate accountability with responsiveness or sanctioning (Philp, 2009). I will return to this conceptual problem below. 
constitutes the foundation of political representation in LD. This transaction can be annulled by withdrawing the delegation, with citizens thus enjoying a sort of priority rule over representatives' decisions.

Descriptive representation is the accurate correspondence or undistorted resemblance between the representative and the represented (Pitkin, 1967, 60). 'Descriptive' here can refer to visible traits (e.g., physical characteristics, biological markers, class divisions, or other social identities), but also to a more substantive, inner correspondence (e.g., standpoints, shared experiences, orientations, opinions, ideas, and the like). In the latter sense, descriptive representation can, under certain circumstances, serve to enhance substantive representation and the representation of citizens' interests (Mansbridge, 1999). ${ }^{3}$ LD seems compatible with descriptive representation of this sort for two interconnected reasons. First, by enabling strong proportionality, ${ }^{4} \mathrm{LD}$ is able to provide a highly accurate image of society and to "reflect with mathematical exactness the various divisions of the electorate" (Pitkin, 1967, 61-62). In fact, advocates of proportional representation argue that it enhances the substantive representation of interests by producing a more plural and inclusive (i.e., descriptive) parliament, Second, since representation in LD is more flexible and granular, the system maximizes citizens' chances of finding their ideal proxy-their "best hope for accurate representation" (Green-Armytage, 2015, 2020). This is the result of the free choice of the proximity basis, ${ }^{5}$ the area specificity of delegations and participation, and the low barriers to participation. Above all, the possibility to choose different proxies for different issues-a unique feature of $\mathrm{LD}$-minimizes the costs of essentialism, acknowledging the obvious impossibility that any single representative can "stand for all constituents in all the thickness of their individuality" (Young, 1997, 362). Unlike 'pure' direct democrats, who claim that only citizens who speak for themselves can advance their interests properly, liquid democrats suggest refurbishing representation and making it more flexible in accommodating individuality. This means that I, as a woman, could at times be represented by other women, but also, at other times, by proxies with whom I share completely different affinities. Overall, LD fosters strong proportionality-and hence descriptive representation-along the dimensions that are (politically) most relevant to each delegator ${ }^{6}$.

\footnotetext{
${ }^{3}$ This does not reduce the need for substantive representation: Democratic representation should aim to represent substantive interests, and this often occurs without any need for descriptive representatives.

${ }^{4} \mathrm{LD}$ enables strong proportional representation thanks to the proxy-voting principle, which requires weighted voting among proxies (Valsangiacomo, 2020, 6). Moreover, the wasting of votes is avoided to a greater extent than in existing proportional electoral systems thanks to the open-seat parliament, with no cap on the number of possible representatives (Valsangiacomo, 2020, 18).

${ }^{5}$ The idea that the criteria for proxy selection (e.g., common interest, shared identity, geographical proximity, etc.) are left to the discretion of the citizen.

${ }^{6}$ This, I would argue, is what really sets LD apart from sortition-based models of democracy. Both schemes aim to produce high levels of descriptive representation, but LD does so by empowering citizens via flexible elections, instead of alienating them via the random selection of public officials.
}

We have seen that LD is compatible with both formalistic and descriptive understandings of representation. This understanding of liquid representation is useful, but incomplete, since it neither leads to a more substantive appreciation of representation in LD nor provides guidance with respect to the proper, substantial function and legitimacy of political representation in LD, leaving us to wonder about "the nature of the activity itself, what goes on during representing, the substance or content of acting for others" (Pitkin, 1967, 114). This is problematic, because a widespread consensus exists that not every existing form of political representation qualifies as democratic (e.g., Pitkin, 2004, 336; Urbinati, 2006, 4; Urbinati and Warren, 2008, 395-397; Rehfeld, 2018, 216-218). ${ }^{7}$ Democratic representation can be seen as a form of political representation in which the intended referent either corresponds to the audience or, at least, serves as an additional, auxiliary audience (Lacey, 2017, 58, 61). ${ }^{8} \mathrm{I}$ follow other scholars in claiming that genuine democratic representation should, ultimately, aim at improving democracy, by fostering the "establishment of meaningful practices of selfgovernment" (Castiglione and Pollak, 2018, 31) and helping "to achieve the ideal of self-rule." (Lacey, 2017, 67) In other words, political representation and representative institutions are democratic when they empower citizens, for example by offering them a powerful tool for inclusion in political life, as well as for advancing their interests in public debates and collective decision-making. Democratic representation is thus "a mode of political participation” rather than exclusion (Urbinati, 2006, 4).

This raises a number of questions: Does LD dilute the concept of representation, by interpreting it in purely formalistic and descriptive terms? If not, what is the most accurate way of understanding political representation under LD? Does LD enable high-quality, democratic representation? The fear that LD reduces representation to a purely formalistic or descriptive act is not baseless. In particular, two major theoretical gaps seem to represent obstacles to a substantive understanding of representation in LD. Since an assessment of representation in LD is hardly possible without first grappling with these two problems, they must now be addressed.

First, the nature of the voter-proxy relationship in $\mathrm{LD}$ is unclear. Traditionally, political representation has been conceptualized as a principal-agent relationship (Urbinati and Warren, 2008, 389), giving rise to an alleged dilemma about whether the agents, i.e., the representatives, should be seen as mandated representatives (delegates) or rather as independent representatives (trustees) of their principals (voters). ${ }^{9}$ For Pitkin,

\footnotetext{
${ }^{7}$ Following a Rousseauian tradition, some theorists might even claim that representation can never be completely democratic (e.g., Manin, 1996; Barber, 2014), an issue that will not be addressed here.

${ }^{8}$ The intended referent corresponds to the represented party (the constituency), whereas the audience is the "the relevant group of people who must recognize a claimant as a representative" (Rehfeld, 2006, 5).

${ }^{9}$ In this article, I use 'mandate vs. independence' and 'delegate vs. trustee' interchangeably to indicate the controversy concerning the discretion enjoyed by the representative when voting. Treating these pairs as synonyms is common in the literature (e.g., Runciman, 2007; Mansbridge, 2011; Blum and Zuber, 2016), although this practice has also been criticized (Rehfeld, 2009).
} 
the mandate-independence tradeoff requires striking the right balance to avoid a "too skewed relationship." (Pitkin, 1967, 155) There are reasons to worry that LD does not achieve this balance: On the surface, the voter-proxy relationship seems to favor the principal, who, thanks to instant recall, enjoys considerably more oversight over the agent than in traditional representative democracies. As Pitkin (1967), 153 points out, when a representative is fully mandated and only carries out orders, no representation takes place: "At most he might be said to stand for them descriptively or symbolically, but not to represent them in his activity." Is this the case with LD? This first research gap is addressed in Of Citizens and Proxies.

Second, due to its unique and innovative voting scheme, LD seems not only to have an affinity with a minimalist-aggregative view of democracy, but also with an individualist-atomistic view of society. Intuitively, LD tends toward a liberal, individualistic understanding of representation, driven by the postulate that individuals are the primary, if not the only, unit of philosophical analysis (Weale, 1981, 457). Unsurprisingly, current research on LD focuses only on citizens and proxies-both qua individual subjects. Yet, several other entities would undoubtedly participate in politics under $\mathrm{LD}$, and the atomistic approach fails to explain which main actors compose the political reality of $\mathrm{LD}$, as well as the nature of the relationship between them (Hay, 2011, 470). This raises concern about entities such as political associations under LD. What would happen to parties and interest groups? Mapping this ontological terrain is necessary in order to situate LD in a broader context and to explain whether LD is compatible with any account of representation other than the classic, liberal one. ${ }^{10}$ This second research gap is addressed in Of Parties and Partisanship.

\section{OF CITIZENS AND PROXIES}

The answer to the question about the proper relationship between citizens and representatives is "the central normative problem" of representative democracy (Rehfeld, $2009,214)$. It is therefore only natural to ask: What is the most accurate way to understand the relationship between citizens and proxies in LD? On the surface, the voter-proxy relationship in LD seems to favor the voter, who formally enjoys considerable oversight over the proxy's work-at least when compared to elected officials in traditional democracies. In light of its unique features, such as voluntary delegation and instant recall, LD might look like a great tool for enabling popular control and incentivizing responsiveness (i.e., the consistency of preferences between citizens and representatives). Unsurprisingly, the reception of these features in the

${ }^{10} \mathrm{By}$ 'classic, liberal account', I mean any theory of representation that adopts an individualist, aggregative focus, a theory that emphasizes the interests of the individuals and assumes pre-political, fixed preferences. In my understanding, this is not dissimilar to what Warren calls the "standard theory of representation" (Warren, 2017, 40). literature has mostly been positive. Yet, some might worry that representation in LD ultimately veers toward a kind of imperative mandate that effectively ties the hands of the proxies. This situation would be problematic, given that, as Vandamme (2020), 2-3 shows in his contribution to this special issue, there is a strong case to be made for some degree of discretion on the part of the representatives.

Clearly, the nature of the voter-proxy relationship under LD requires more study: Is liquid representation the new bastion of popular rule, or does it unduly reduce representation to a mere transaction scheme of delegations and predefined choices? The answer lies somewhere in the middle. For instance, Blum and Zuber (2016) propose to redefine representation in $\mathrm{LD}$ as a halfway point between pure delegation and complete trusteeship. At the end of their article, they suggest that proxies should act as both delegates and trustees, arguing that the principals should ultimately decide whether the "conflict between their interests and the actions taken by the representative" is unbearable (Blum and Zuber, 2016, 180). This section takes up the challenge of elucidating how and why this should be the case. More specifically, it proposes to use the selection model of representation as a sound normative benchmark for shaping and evaluating liquid representation. In the following paragraphs, I will introduce the selection model, explain why it is apt for-and can be transposed to- $-\mathrm{LD}$ (3.1), show why the instant recall complicates this claim without undermining it (3.2), and identify the normative implications of this view (3.3).

\section{Selection in Liquid Democracy}

The selection model of representation, which is opposed to a sanction model of representation, has been resurrected by Jane Mansbridge (2009). This descriptive and normative model explains representation as follows: When voters (principals) are looking for a representative (agent), they invest time in selecting agents who can be expected to act mainly for internal reasons, in line with the principals' own preferences or interests. Mansbridge also refers to these agents as "introspective" (Mansbridge, 1999, 644) or "gyroscopic" representatives (Mansbridge, 2003, 520, 2011, 624). For this dynamic to occur, three general conditions must be satisfied: first, the availability of self-motivated agents; second, the prior alignment of principal-agent objectives; and third, a relatively unproblematic and accurate selection process (Mansbridge, 2009, 370). When institutions secure these general conditions, the balance favors a selection model rather than a sanction model, ${ }^{11}$ because it becomes more efficient for the principals "[...] to invest resources, ex ante, in selecting the required type rather than investing, ex post, in monitoring and sanctioning" (Mansbridge, 2009, 369).

Creating an environment that emphasizes and favors selection rather than sanctions is desirable, because selection is akin to an

\footnotetext{
${ }^{11}$ According to Mansbridge, the sanction model is nowadays more commonly used by political scientists to explain representation: "in this model, the interests of the principals (in politics, the constituents) are assumed to conflict with the interests of their agent (the representative). The principals must therefore monitor the agent closely, rewarding the good behavior and punishing the bad" (Mansbridge, 2009, 369).
} 
"integrity-based system of public office," which solicits virtuous behavior from the representatives (Philp, 2009, 37-38). This probity, in turn, strengthens trust in and the legitimacy of representative institutions. In the following paragraphs, I will show why LD fulfills the three abovementioned conditions, which renders selection based on mutual trust less costly and more attractive, making LD a promising means for the realization of Mansbridge's selection model of representation.

First of all, it is necessary to show that intrinsically motivated agents will be widely available in LD and that they will not be driven out by extrinsically motivated, self-interested agents. Generally speaking, public offices are likely to attract agents "[...] whose intrinsic motivations include what might be called public spirit, that is, concern with the common good and at least some willingness to make sacrifices in material interest for that good" (Mansbridge, 2009, 378). This is particularly the case when, as in $\mathrm{LD}$, running for office is open to all citizens and nobody is forced to become (or is prevented from becoming) a proxy. In other words, when the choice to run is voluntary, a self-selection process is likely to take place. Self-selection prompted by intrinsic motivations is even more likely to take place if the system is free from corruption and if the pecuniary rewards are correctly balanced. In $\mathrm{LD}$, remuneration and safety could present technical difficulties: The number of proxies could be much higher than it is today, which could lead either to an explosion in the cost of elected officials or to a fall in wages for elected public officers (Ford, 2002; Green-Armytage, 2015, 203-204). Similarly, online voting poses challenges for developers and computer scientists with regard to the trade-off between secret ballot and voter-verification (e.g., Behrens et al., 2020, 43-56; Paulin, 2019, 73). Neither issue is insurmountable and both must be addressed in order to enable self-selection. Moreover, Mansbridge (2009), 380 stresses that competence itself (or specialization) fosters greater internal motivation-a condition that LD seems inherently to satisfy. LD incentivizes the diversification of candidates, meaning that proxies can run for office either as generalists or as specialists. Generalists are the equivalent of candidates today, who present a broad (partisan) policy agenda and who are willing to represent voters in all policy domains. By contrast, other proxies might prefer to mobilize only selectively, proposing a narrower or even single-issue agenda. The figure of the 'policy area expert' further favors intrinsic motivation, as proxies can selectively pick out and invest in those areas that match their own interests and expertize (Blum and Zuber, 2016, 168). Finally, perfect proportional representation is a further incentive for proxies to follow their own convictions, political visions, and judgments (and, in turn, to be less responsive to the threat of sanctions). In fact, when the competition for seats is removed, ${ }^{12}$ the risk of strategic voting on

\footnotetext{
${ }^{12}$ Competition for seats is eliminated because, if there is no limit on the number of possible proxies, there is also no quorum to enter parliament and represent others (Valsangiacomo, 2020,6). By contrast, competition for political and legislative success is not removed. The latter, however, is arguably very different in nature and scope from the former: Electoral success is the conditio sine qua non of any political ambitions that candidates and parties might have. Elections are about getting a seat at the decision-making table, which is why they are so much harsher and more antagonistic. By contrast, once parliamentary work starts, all elected representatives know that they must accept a certain degree of openness to debate, collaboration, and compromise.
}

the part of the voters, as well as the risk of anticipatory strategies on the part of the parties, is greatly reduced if not completely eliminated (Coleman, 1995). Overall, as would be expected to happen under "appropriate conditions," proxies could more easily "sort themselves into jobs and organizations whose aims match their own intrinsic motivation as closely as possible." (Mansbridge, 2009, 381).

For the selection model to work, it is also important that the objectives of proxies and their original voters remain aligned. Here, a series of contextual variables play a vital role, affecting supply and demand with respect to aligned interests. On the supply side, Mansbridge holds that districts should be as homogeneous as possible (Mansbridge, 2009, 380). This requirement is not needed in $\mathrm{LD}$, which makes use of proportional representation and in which constituencies transcend territorial borders: Any original voter can select any proxy from anywhere in the country, an arrangement that is expected to maximize the alignment of objectives, despite the diversity of opinions. ${ }^{13}$ Moreover, norms and institutions that prevent corruption are expected to keep interests aligned during the period of representation (Mansbridge, 2009, 380). Finally, the presence of policy-area experts sets the bar for competence higher, which in turn fosters intrinsic motivation, increasing the "supply of aligned potential agents" (Mansbridge, 2009, 380). On the demand side, the need for aligned objectives depends partly on the activity that the proxy is expected to perform: The selection of agents with closely aligned goals is worthwhile when the agents are hired for long-term, creative, and complex tasks requiring adaptability, flexibility, and dedication. In these circumstances, principals are more ready to tolerate some divergence and accept the agents" "selfreliance in judgments" (Mansbridge, 2011, 621). LD provides a more demand-stimulating context than existing democracies, since the proxy-mandates are, de facto, open-ended contracts that are valid until they are recalled ${ }^{14}$.

Finally, it must be shown that LD supports "accurate selection" and accommodates "the capacity to 'de-select' easily when circumstances change" (Mansbridge, 2009, 381). The availability of intrinsically motivated agents whose goals are aligned with those of the citizens is less important in cases where citizens are poorly informed about the available options. Thus, an environment is needed that favors the circulation of reliable information, so that citizens can make informed decisions about their representatives. Generally speaking, voters can rely on shortcuts, such as costly signals, good reputations, and stereotypes in order to form an opinion of the candidates' characters and goals, with the party and media systems playing a key informational role as well (Mansbridge 2009, 381). As

\footnotetext{
${ }^{13}$ Mansbridge assumes a first-past-the-post, single-member-district electoral system akin to the American one. By contrast, LD is (by nature) a proportional-representation system, and hence supports multi-member districts. As such, districts could be rather large in order to allow voters to maximize their chances of finding an ideal representative using any proximity basis they prefer. ${ }^{14}$ In order to make sure that original voters do not neglect their political duties by delegating their votes once and for all and by alienating themselves from politics, measures could be adopted such as the regular invitation to renew or withdraw one's delegations, or the convocation of formal, nationwide elections every $\mathrm{x}$-number of years.
} 
will be seen in Of Parties and Partisanship, we have no reason to doubt that parties and partisans will act as watchdogs under LD. Just as they currently do, parties and partisans will be able to act as a check on the operations of each other's elected officeholders. Similarly, a candidate's membership in a given party or political association provides citizens with a useful heuristic for evaluating his or her motivations and goals.

Finally, I argue that a unique feature of $\mathrm{LD}$, so-called metadelegation, inherently promotes accurate (de-)selection and paves the way for a selection model of representation in two interrelated ways. First, because metadelegation provides considerable epistemic value (Valsangiacomo, 2020), citizens who wish to have a wide and diverse set of representatives do not need to feel daunted by the task of finding the ultimate representative for every issue. ${ }^{15}$ Instead, they can rely on a trusted, first-level proxy who will take care of representing them in parliament or, if need be, re-delegating their vote to a further proxy. ${ }^{16}$ This provides relief to the citizens, who might feel safer "selecting on character" rather than electoral promises, agenda or expertize (Mansbridge, 2009, 381). Second, long chains of metadelegation make the idea of post-election monitoring quite unappealing and burdensome. It is true that the original voters can easily de-select the proxies via instant recall, but why would they rationally want to enter a vicious loop of making rushed decisions, regretting their badly informed decisions, going through a costly monitoring process, sanctioning the proxy, and repeating everything all over again? On the assumption that no one wants to be systematically misrepresented, the original voters are prompted to invest, ex ante, in looking for a reliable proxy, because the costs of repeatedly monitoring, ex post, the entire metadelegation chain would be too high ${ }^{17}$.

\section{A Selection Core With a Sanction Periphery}

Mansbridge argues that for representatives to stay engaged and internally motivated, they need to feel trusted and not under constant "police-patrol oversight" (Mansbridge, 2009, 385). In a selection model of representation, in which representatives are deemed to be honest and intrinsically aligned to their constituency, citizens and civil society have reason to become alarmed only if they encounter obvious wrongdoing (e.g., as reported by the media or by political adversaries). Therefore, "transparency in rationale"-e.g., making procedures,

\footnotetext{
${ }^{15}$ Note, however, that voters are free to decide whether to split their voting power among several proxies or to delegate it entirely to a single proxy. Moreover, voters could also decide to attach various restrictions to their votes, limiting for example the number of redelegations allowed (Valsangiacomo, 2020, 9).

${ }^{16} \mathrm{~A}$ first-level proxy does not need to be someone the citizen knows personally, like a friend or a relative, but can simply be someone whom the citizen can trust according to the selection model-namely someone who, given the information available, can be expected to act on the basis of intrinsic motivations and to pursue congenial policy goals.

${ }^{17}$ This seems to hold true regardless of how transparent and accessible chains of metadelegation are, since transparency does not automatically counterbalance complexity or make information more comprehensible. The question of whether $\mathrm{LD}$ is more burdensome for citizens than traditional democracies could be a topic of future empirical research.
}

information, reasons, and facts transparent-is preferred over "transparency in process"-e.g., requiring that all committee meetings be public (Mansbridge, 2009, 386). For several reasons, some degree of systematic and ongoing public scrutiny in the process is, however, unavoidable in LD. To begin with, it has been argued elsewhere that all formal decisions made by proxies (about their votes or redelegations) must be public to allow for transparency (Valsangiacomo, 2020, 14-15). In line with the "golden rule" of vote transparency (Hardt and Lopes, 2016), the original voter in LD enjoys the right to supervise the entire chain of delegation and can thus keep track of the whole process and of all the decisions made by his or her proxies at all levels of delegation. Furthermore, the sessions of the liquid parliament would be open in order to allow all individual, original voters to participate. There might be instances where representatives meet and deliberate privately, ${ }^{18}$ but the LD model tends to favor full transparency.

In an ideal selection model, not only is the close monitoring of elected officeholders considered a second-order priority, but sanctions are also seen as an option of last resort. In contrast to an ideal sanction model, where accountability is usually replaced by or even equated with full responsiveness or punishment, accountability in a selection model means rather explaining one's conduct and giving reasons for divergence. ${ }^{19}$ Whereas principals do not constantly threaten to throw agents out of office, whenever the latter's actions deviate from the former's preferences on certain issues, the agent has a duty to be narratively or deliberatively accountable and to provide reasonable explanations for this deviation to the constituency. ${ }^{20}$ However, there is one aspect of LD that appears to contradict and potentially inhibit this dynamic. The instant-recall principle puts the representatives under a sword of Damocles, since their delegations can be easily withdrawn at any time and without appeal. This creates room for a "harshness objection," to the effect that such a powerful sanctioning tool serves as an individual public trial that ultimately renders the prospect of becoming a proxy unattractive (Vandamme, 2020, 13-14). Yet, I suspect that this critique underestimates the importance and efficacy of other mechanisms that typically ensure the fulfillment of the duty of accountability in democracy, such as exposure on social media, pressure from political opponents and public opinion, systemic checks and balances, subjection to the rule of law, anti-corruption audits, and so on. Ultimately, the instant recall is an additional, lastresort option available to citizens in case of extreme misconduct or obstinacy in concealing information by the proxies.

\footnotetext{
${ }^{18}$ For instance, in the case of informal, personal meetings, but even in formal situations, if the agents deem it useful and productive. In this regard, an important, open issue concerns how to regulate the work done in and by parliamentary commissions.

${ }^{19}$ This corresponds to accountability as defined by Philp (2009), 32.

${ }^{20}$ This happens by publicly addressing the constituency at large (e.g., during a rally, at a press conference or in a public interview, on both traditional and social media, etc.), as well as in more targeted, private settings (e.g., answering messages and calls from individuals and groups, meeting with supporters, etc.).
} 
Still, one might wonder whether the ideas of instant recall and gyroscopic proxies are fundamentally compatible. Proxies might initially be self-reliant in their judgment but, over time, can their intrinsic motivations be pushed out by the pressure put on them through the looming presence of instant recall? Although this possibility cannot be ruled out at the moment, the answer seems to depend on the strength of the proxies' passionate commitment and on the ability of the instant recall to systematically undermine integrity and judgment. I suspect that 1) it is not the mere possibility of being recalled per se that reduces self-motivation, but rather the effective and systemic use that is made of monitoring and sanctioning and that 2) the effective, systemic resort to instant recall depends, in turn, on the ethical culture within the public system. This implies that a loop might be occur in either direction: If $\mathrm{LD}$ is implemented in a way that rather supports the sanction model, the instant recall undermines autonomy, insofar as it can be too easily seen and used as a tool for pushing the proxy into producing a predetermined result (vicious loop). By contrast, if LD is implemented in a way that supports the selection model, the instant recall does not undermine-and might even reinforce-proxies' integrity and autonomy of judgment, because their motivations are not extrinsic (virtuous loop). The core of the selection model is the assumption that, if the context permits it, voters will naturally tend to select representatives who are trustworthy, intrinsically motivated, and aligned with their own goals. By definition, these gyroscopic proxies will not change their behavior simply to avoid the potential recall of delegations, just as honest employees will not stop doing a good job only because their company could fire them at any time. Similarly, it is unclear why voters who chose gyroscopic proxies in the first place would recall their delegations over any single instance of divergence, just as it is unclear why an employer who tries to hire honest, independent employees would fire them whenever they act differently than the employer would have done. ${ }^{21}$ Therefore, by enabling open-ended mandates, the main function of the instant recall is simply to turn delegations into a kind of permanent employment contract.

To sum up, the potential dissonance between instant recall and selection should be taken as a serious and major concern. At the same time, it seems that the possibility of recalling proxies is compatible with their relative independence, when the instant recall is used in a context that favors selection in the first place. The analysis presented in the previous section shows that this is not unlikely, since there seem to be enough factors that make LD akin to Mansbridge's selective model of representation. Of course, this does not imply that the alignment of objectives is always absolute or that internal motivation is never corruptible. Even though LD promotes a selection model of representation, it is not necessary for aspects of the sanction model to disappear

\footnotetext{
${ }^{21}$ Of course, discretion can sometimes backfire: grave mistakes could still be made and the code of ethics could be infringed upon. There is no doubt that this misconduct should and would be punished, but the point of selection is that voters will largely select trustworthy and honest representatives in the first place. Moreover, it is clear that, even in a selection model, safety mechanisms, such as the rule of law or checks and balances still need to be preserved.
}

(Mansbridge, 2011, 622). Hence, even under a selection model of representation, the instant recall could be interpreted as "an additional opportunity for citizens to keep their representatives [proxies] in check" (Vandamme, 2020, 5). Indeed, this speaks in favor of the hypothesis that LD can strive to realize a selection core with a sanction periphery.

\section{Normative Implications of Selection}

There are a series of relevant normative implications that derive from coupling LD with a selection model of representation. In what follows, I discuss three important domains of LD affected by gyroscopic representation: the mandate-independence dilemma, the principle of anti-elitism, and the centrality of deliberation.

\section{Mandate Vs. Independence}

As argued by Blum and Zuber (2016), 180, LD should strike a balance between delegate and trustee views of representation. The selection model introduced above is helpful for understanding how LD manages to reconcile the autonomy and the interdependence of voters and proxies. In fact, selection depends on the existence of "self-reliant representatives who are relatively unresponsive to sanctions" (Mansbridge, 2011, 622). These gyroscopic representatives act on the basis of internal convictions. They have their own vision of the common good and are not driven by concerns about (re) election. Since their intrinsic goals are shared by their constituents, once selected, gyroscopic representatives can be entrusted with considerable discretion and autonomy of judgment. Unsurprisingly, Mansbridge (2011), 621 proposes to completely replace the notion of trusteeship with that of selection.

The concept of gyroscopic proxies clearly rescue LD from accusations that it disempowers representatives by reducing representation to a formal, descriptive fact. The distinctive role of gyroscopic proxies requires that they be granted a certain autonomy of judgment in order to successfully pursue their common projects in parliament, where they must deliberate, cooperate, and negotiate with others.

Nevertheless, autonomy of judgment does not imply the transformation of proxies into completely detached, independent trustees. There are three reasons for this: First, proxies remain aligned with their constituents through their intrinsic motivations. Second, they are answerable for their conduct to their constituents. Third, they remain subject to public scrutiny and, potentially, to the instant recall of their delegations. As mentioned above, autonomy of judgment and instant recall are not necessarily in conflict, as long as they are found in a context that favors selection, such as the one provided by LD. A given citizen chooses a representative on the assumption that this person "will act much the same way the voter would if placed in the legislature." (Mansbridge, 2003, 522) Through this fiduciary transaction, the original voters do not renounce their voting power, but instead use that power to select a proxy who shares their objectives and, if their goals are no longer aligned, to remove the proxy from office.

Just like representatives in Nadia Urbinati's theory of advocacy, proxy representation captures "the complex character of representation-its commitment to as well as its 
detachment from a cause" (Urbinati, 2006, 45). It is the "ideological as perspectival similarity" between citizens and proxies, induced by selection, which enables gyroscopic proxies to be different to and independent from, yet also similar and responsive to, their constituency (Urbinati, 2006, 50).

\section{Anti-elitism}

One condition for trust in selection and LD is the assumption that, had the original voter experienced the decision-making process directly (e.g., acquired first-hand knowledge of participation in parliamentary deliberation), that person would not have reached radically different conclusions from those actually reached by the proxy. Thus, gyroscopic representation emphasizes the idea of "likeness" or "resemblance" (Mansbridge, $2009,386,2011,623)$. One might say that the selection model places the "sympathy of ideas and views" at center stage, where sympathy does not presuppose the existential identity of representative and represented, but rather indicates "reflective adhesion" to the social specificity of one's own constituency (Urbinati, 2006, 45, 49). It serves the purpose of creating a "passionate link to the elector's cause," as well as of "nurtur [ing] the spirit of controversy" (Urbinati, 2006, 45). In other words, sympathy denotes the representatives' capacity to "possess the same sentiments and feelings" as their constituency (Mansbridge, 2009, 387), which is arguably a "more humanly satisfying” basis for a relationship (Mansbridge, 2009, 371).

From this claim, a second consequence follows, concerning the distinct anti-elitism endogenous to LD. I will argue that sympathy, in this sense, precludes any superiority on the part of the representative, as well as any serious distrust toward the represented masses. The notion of gyroscopic proxies challenges the principle of distinction, as well as democratic elitism as a broader prescriptive theory, according to which a good representative is necessarily an aristocrat, an alien who 'naturally ranks higher,' whether in terms of virtue, wisdom, intelligence, charisma, or talent. This anti-elitist and antipaternalistic normative position is central to $\mathrm{LD}$, in which the legislator is not always a representative. In fact, in the context of LD, where the legislative body can be composed of both proxies and individual citizens, a principle of distinction is untenable, because it would delegitimize the individual citizen's direct participation in the legislature.

At the same, this normative position neither challenges the idea of a democratic division of labor nor rules out the possibility that certain social and psychological types might in reality be more likely to become proxies. After all, "[...] advocacy, like election [and like delegations], entails a selection because we seek to get the best defendant, not a copy of ourselves." (Urbinati, 2000, 76) As a matter of fact, LD has previously been characterized as epistemically superior to existing representative democracies, precisely because it is expected to mobilize more policy-area expertize (Blum and Zuber, 2016, 167-169).

Nonetheless, becoming a proxy is not a prerogative of experts or charismatic individuals. Even when citizens choose to be represented by a proxy, what matters in $\mathrm{LD}$ is the connection that such a selection enables. Proxies can differ in important respects from their constituencies and still be responsive, because they are, to a large extent, similar to them. This aspect could not be accounted for by elitist understandings of democracy. In fact, gyroscopic representation-and hence LD-eschews the hierarchy endorsed by thinkers like Edmund Burke and Joseph Schumpeter (Mansbridge, 2009, 386, 2011, 623).

Overall, “when voters say they want to select a 'good man' or 'good woman' as a representative, they often seem to want someone like them, but with the interest, competence, and honesty to be a legislator" (Mansbridge, 2009, 387). Proxies are not elected aristocrats, but trusted defendants who will advance, reproduce, and author claims within the political discourse in the name of their voters. Hence, the principle of difference in LD should be qualified, if at all, as profoundly antielitist and democratic.

\section{Deliberation}

Another important implication of the selection model is that it enables the reconciliation of LD with central tenets of deliberative democracy and, more generally, with the constructivist turn (Warren, 2017, 44). To explain why this is the case, consider first how a selection model shifts the focus from 'control over the representative' to 'control over the legislature.' In the extreme case, "a pure selection model" (Mansbridge, 2009, 390), the voters cannot be seen as properly controlling the autonomous, gyroscopic representatives. That is, voters do not aim to influence the views of their proxies. The latter are the chosen instrument through which citizens influence decision-making: "[V]oters get the legislature to do what it would otherwise not do by placing in it a representative who will pursue the policies that they favor. The voters' ultimate goal is not control over a particular representative but a fair share of control over the entire legislature." (Mansbridge, 2009, 390) Given that the pure selection model is a regulative ideal and, in practice, is often mixed with aspects of the sanction model (as in the case of LD), the shift toward 'control over the legislature' is doubly relevant for LD.

First, it further flattens out the differences between proxies and original voters, insofar as both are seen as potential legislators. It also prevents a discrepancy from emerging between those who vote directly and those who delegate. In other words, LD emphasizes collaboration in collective decision-making rather than mere participation in elections as the primordial role of citizens.

Second, deliberation once again becomes central. In the first instance, this concerns vertical communication between voters and proxies. Despite being rather unresponsive to the direct control of the represented and acting autonomously, the gyroscopic representative is not unaccountable, since they have to give an account of their actions to voters (Philp, 2009, 32). A discursive relationship-a sort of "(one-way) narrative accountability or (two-way) deliberative accountability" (Mansbridge, 2009, 384)-arizes naturally in a context in which the bond between representative and represented depends on the alignment of objectives and ideological sympathy. Here, principals can be dissatisfied with specific policies or results, but this does not really undermine trust in 
their agents as long as there exist arguments showing that the "intrinsic motivation underlying the aligned objectives remains unchanged” (Mansbridge, 2009, 384). This vertical communication implies, normatively speaking, that representatives and constituents are open to reciprocal persuasion and influence. This makes LD compatible with the notion that, beyond being an institutional matter, representation includes a dynamic, performative, and creative process as well: "Representing is performing, is action by actors" (Saward, 2006, 302). This interactive and discursive process of representation itself actively shapes the voter-proxy relationship, contributing to the construction and engagement of autonomous citizens.

At the same time, the shift of attention toward the legislature hints at the centrality of deliberation in parliament. As we have seen, proxies are expected to convey their particular views to parliament and to defend them passionately. This highlights the complex nature of the work of representatives in $\mathrm{LD}$, which goes well beyond the transmission of preferences or the mirroring of existing social configurations. In particular, gyroscopic representation presupposes the existence of a competitive parliamentary space, which is the sole forum in which representatives can meaningfully exercise their political function. In this space, gyroscopic proxies can pursue their causes, while confronting those of other representatives in accordance with the principles and procedures of democratic government. What the liquid parliament would look like and how it would work is unfortunately still unclear. What is clear is that, to rephrase Urbinati $(2006,46)$, without parliamentary deliberation, there would be no reason for gyroscopic representation or representation by proxy in LD.

\section{OF PARTIES AND PARTISANSHIP}

Even though the discussion in Of Citizens and Proxies might have already cast doubt on the ties between LD and a purely aggregative view of democracy, one might still worry about LD's affinity with a strongly individualist view of society. This concern is exemplified by the almost exclusive focus in the existing literature on citizens and proxies, both conceptualized $q u a$ individual subjects, without any reference to associational life. More questionably, an implicit assumption lingers in the literature that LD might tear down any intermediary political institutions. For example, Blum and Zuber (2016), 178 write that "[p]arties as coordinating mechanisms are superfluous since members of the community either participate directly or delegate their votes on the basis of individual relationships with their delegate."

This section therefore addresses the following questions: What happens to familiar categories of associational life, such as parties and interest groups, under LD? Does LD convert parties and party politics into zombie categories? Can the gyroscopic proxies be members of a party or must they be independent? In answer to this, I will argue that, while LD does blur the lines between parties, interest groups, and voluntary associations, it does so without necessarily eliminating party structures and, most importantly, without diluting partisanship. In what follows, I will show that the political ontology of LD can encompass more than individual citizens and proxies (4.1), outline the challenges faced by parties as organizations in LD (4.2), explain why LD does not imply the abandonment of partisanship (4.3), and discuss whether individual proxies can be partisan (4.4).

\section{Associational Life in Liquid Democracy}

The claim that LD threatens associational life as such is misleading. Unless the right of association is explicitly forbidden, no form of government can prevent the formation of groupings in civil society. It is, therefore, more meaningful to ask whether LD poses a challenge to associational life as we know it. Since it would be impossible to fully cover this broad topic here, I will restrict my analysis to political associations. This kind of association is characterized by the fact that it is usually voluntary, collective (non-intimate), and based on a common purpose, which is embodied by an extrinsic political goal (Brownlee and Jenkins, 2019). Two political organizations, in particular, stand out for their unique institutional role as political intermediaries and deserve special attention: political parties and interest groups $^{22}$.

Political parties and interest groups are among the central research topics in political science. ${ }^{23}$ From a formal point of view, they are usually conceptualized as quite similar, but nonetheless distinct entities. On the one hand, they share important attributes. For instance, both parties and groups are political associations that actively mediate the relationship between society and government. Both attract citizens and mobilize them to action and both seek to influence policymaking. On the other hand, parties and groups differ in certain respects. Most importantly, modern parties are the only political group or association explicitly organized for the sake of exercising power or governing: Only parties formally compete for offices and vie for electors' votes (White, 2006, 2-3). Analytically speaking, Rosenblum sets parties apart from other groups on the basis of three distinguishing features: 1) context, because parties emerge only in political societies where there is government and where there are offices to be held; 2) aims, because parties are institutions dedicated to ongoing political activity, which operate in public view and are able to hold office, as well as to participate in government; 3) members, because modern parties have a large partisan base, which attracts a substantial number of followers (Rosenblum, 2008, 18-21).

Legally speaking, in almost all existing democracies, political parties are legal entities whose formal role is usually protected by the constitution and/or statutory party laws (Rosenblum, 2008, 419). Parties thus differ from other political associations, insofar as they are the only entities legally permitted to participate in the electoral process. Other associations are relegated to nonelectoral representation at best, being de facto precluded from playing a direct role within the electoral process, hence organized

\footnotetext{
${ }^{22}$ Also known as interest groups, pressure groups, advocacy groups, or lobbies.

${ }^{23}$ The literature on this topic is rich and extensive and cannot be done justice here. The following discussion will necessarily be quite abstract and its conclusions will ideally be relevant for all possible cases and types of political parties and interest groups.
} 
interest groups typically seek to exert influence over policymaking by pressuring elected officials ${ }^{24}$.

LD seemingly calls this formal-legal artifact into question, because interest groups can take on a more direct role as they find new and affordable points of entry into policymaking. In fact, as a result of policy-area expertize, LD offers any pressure group the opportunity to selectively engage in electoral representation in its area of competence and interest. If, for example, members of the car-manufacturing industry support looser regulations on carbon emissions, they can select a group proxy to campaign and defend their cause, instead of lobbying an elected representative. At the same time, in place of, or in addition to, street protests to block this new law, members of environmental associations can vote en masse against it $^{25}$.

Blurring the traditional division between parties and other associations raises manifold questions: Which groups should own or join the electoral and legislative process? Is it normatively problematic to put parties and groups on a level playing field? That is, can interest groups be agents of democratic representation? The classic (legal) distinction is clearly useless for addressing these questions in the context of LD: Parties are, by definition, those associations allowed to participate in elections and lawmaking and if all groups suddenly enjoy this right, distinguishing parties from interest groups will become impossible. A clearer understanding of the role of parties in representative democracies is thus needed. Parties have both a pragmatic and a substantive value for democracy, and it is crucial to assess whether LD is at risk of losing this, by blurring the boundary between parties and interest groups. The next two subsections will address these aspects of parties, showing that LD challenges party structures without necessarily endangering partisanship itself.

\section{A Challenge for Party Structure and Its Functions}

Modern parties appear essential to democratic practice and no existing democracy seems able to do without them. Indeed "modern democracy is unthinkable save in terms of parties." (Schattschneider, 1942, 1) The list of beneficial functions typically assigned to parties is long: e.g., parties identify and trace conflict lines, create political agendas, monitor each other and check the executive, mobilize and educate voters, aggregate interests and opinions, and act as intermediaries between government and civil society (Sartori, 2005, 23-24). According to Rosenblum (2008), Ch. 3, parties have come to fulfill two valuable functions in democracy: First, they regulate competition, making managed, non-violent conflict possible-or as Fossum (2018) puts it, they enable the

\footnotetext{
${ }^{24}$ In some circumstances, interest groups can participate in policymaking via consultation. This is the case in countries that adopt elements of neocorporatism, like tripartism in many European countries or the Vernehmlassungsverfahren in Switzerland and Austria.

${ }^{25}$ Although it fails to clearly distinguish between members, partisans, and activists, this example is quite illustrative of how the political landscape might radically change under LD.
}

peaceful handling of conflict. Second, since they possess the capacity, resources, and willingness to effectively run the government, they are also responsible for governing.

Most pragmatic appreciations are based on a clear understanding of the party qua organization. The party is a collective agent that intentionally coordinates political actions, endowed with "an internal decision-making structure all its own" (Goodin, 2008, 206). In other words, its essence and value is perceived to lie in its formal, bureaucratic apparatus: "[...] the formal machinery of party ranging from local committees (precinct, ward, or town) up to state central committees, and the people who man and direct there." (White, 2006, 5) The political party therefore becomes synonymous with "The Organization" or "The Machine" that is prized for its institutional value (Rosenblum, 2008, 172-175).

In $\mathrm{LD}$, however, this machinery comes under pressure because, as we have seen, parties are no longer the sole form of association capable of participating in elections and government. Whether this would result in the elimination of party organizations is difficult to predict. I suspect, however, that this fear is overblown. LD does not do away with competition for delegations, such that the most ambitious proxies, at least, might still need to unite around common platforms in pursuit of political success. ${ }^{26}$ Moreover, if party structure represents the most successful organizational model, many smaller and informal political associations might be incentivized to reorganize themselves along these lines. The loss of parties qua organizations thus seems problematic only on the assumption that interest groups and other political associations, with their different structures, will be unable or unwilling to fulfill the functions that parties typically fulfill in a democracy. After all, if different organizational structures can produce the same outcome, the disappearance of parties is not an objection to LD. Indeed, even Goodin's imaginary "noparty democracy" could salvaged by the presence of some form of lists, slates, parties, factions, or groups that provide some intentionality and coordination (2008, 2005-206).

The opening of the parliamentary arena to associations other than political parties could nevertheless create new problems. For example, a scenario in which a myriad of different interest groups join the policymaking process qua special-interest groups would pave the way for a pluralist or corporatist theory of democracy, based on the highly contentious notion of functional representation (Couperus, 2019). This is also problematic because "[a]rrant interest group pluralism is not just chaotic and an obstacle to coherent policy; the result can be 'ungovernability."' (Rosenblum, 2008, 133). ${ }^{27}$ Future studies could further investigate these pragmatic arguments against $\mathrm{LD}$.

\footnotetext{
${ }^{26}$ This idea of partisan proxies will be developed in more detail in Independent and Partisan Proxies.

${ }^{27}$ Without considering, in addition to the danger of ungovernability, other equally problematic consequences, like the aggravation of extreme inequalities among groups, the overrepresentation of small, powerful groups, and the resulting specter of oligarchy.
} 


\section{Boosting Partisanship}

Any defense of the instrumental role of parties would be incomplete without a demonstration that parties perform their function "in a way that is compatible with democratic principles." (Chapman, 2020, 3) This more substantial, 'philosophical' appreciation has been developed in recent years by a handful of political theorists (Rosenblum, 2008; White and Ypi, 2011; Muirhead, 2014; Efthymiou, 2018). These theorists agree on many points, above all on the emphasis placed on partisanship as a "regulative ideal" for democracy (Chapman, 2020, 3-5). Partisanship is variously defined as "the distinctive political identity of representative democracy" (Rosenblum, 2008, 366), as "a practice that involves citizens acting to promote certain shared normative commitments according to a distinctive interpretation of the public good" (White and Ypi, 2011, 382), as "commitment to a political party" (Efthymiou, 2018, 194), as "the political orientation of citizens who stand with a party" (Muirhead, 2006, 714), and finally as "party spirit" or spirited and prideful identification (Muirhead, 2014, x). Behind all these definitions lies the idea that partisanship bears a certain moral distinctiveness and "exhibits normatively valuable qualities" (Efthymiou, 2018, 195). According to Rosenblum (2008), 362, partisanship entails "identification with others in a system of regulated rivalry." It is a form of social identity that is more inclusive and comprehensive, rendering those who possess it more ready to compromise compared to other identities, which can be included in-but are always altered and transcended by-partisan identity. Partisans are intimately and inextricably connected to representative democracy, and representative democracy, in turn, benefits from partisans. Where partisanship is widespread, there is acceptance of opposition, awareness of the provisional nature of politics and, most importantly, acknowledgment of one's own partiality. Where partisanship emerges, politics is more stable, participative, and creative. A partisan citizen "displays a democratic sympathy, a willingness to compromise, to give and to take, and (perhaps most of all) to bear the burdens of standing with one's fellow citizens" (Muirhead, 2006, 719).

An important element that cuts across all these works is the explicit choice to conceptualize partisanship separately from parties as organizations. These thinkers all conclude that partisanship is a fundamental virtue, which should be preserved and defended in any healthy democratic system, because it is the only political identity that genuinely enables political pluralism in representative democracy. For some thinkers, a certain ethics of partisanship must be adhered to in order to realize this regulative ideal (Muirhead, 2006, 724; Rosenblum, 2008, Ch. 8). However, the implications of this conclusion for parties as organizations are not straightforward. On the one hand, none of the thinkers cited is particularly indulgent with regard to the status quo of contemporary party politics. They clearly foresee the possibility that existing party organizations may fail to live up to their regulative ideals. On the other hand, the plea for partisanship seem to entail an implicit justification of parties, insofar as partisan organizations are conceptualized as the carriers of partisanship par excellence. ${ }^{28} \mathrm{I}$

${ }^{28}$ This is argued most emblematically and convincingly in Rosenblum (2008), Ch. 7, but see also Muirhead (2014), 110, as well as White and Ypi (2011), 393. hypothesize that this conclusion is valid only under the assumption that party organizations have a legal monopoly on running for office-an assumption that disappears in LD.

At this stage, an important question remains unsettled: Are partisans the only legitimate carriers of partisanship, or can interest groups do just as well? The idea of interest groups as carriers of partisanship is likely to provoke skepticism, because groups generally "retain much of the stigma of factions in relation to the general interest." (Epstein, 1986, 25) It is implicitly assumed that interest groups do not serve the public good and do not even want to-they merely pursue their narrow, sectarian self-interest. Interestingly enough, although a party, too, represents only part of society, it is acquitted of the charge of factionalism because it advances a conception of the public good, "a comprehensive public story about the economic, social, and moral changes of the time and about national security." (Rosenblum, 2008, 358) What prevents us from drawing the same conclusion about interest groups? The existing literature on partisanship does not seem to provide a straightforward answer.

White and Ypi (2011), 384 argue that the distinction between parties and factions (and hence, between parties and interest groups) hinges on their declared aims and motivations: "[...] at stake is not whether, in the eyes of the observer, a political grouping reliably does serve the public good [...], but whether it seeks to do so given the kinds of argumentation it pursues." The effort to put forth such a comprehensive vision of the common good explains the intuitive distinction between a niche or singleissue party, like the Green Party, and any other environmental association. A party is not a party "unless it integrates [its] interests into a wider normative vision addressed to the good of the political community at large." (White and Ypi, 2011, 384) Following this logic, it appears that an interest group can be or become a party (in the sense of being a carrier of partisanship) as long as its members stand together and publicly declare that the particular policies they promote ultimately serve justice, in a broader sense, and public interest. ${ }^{29}$ This shifts the focus to justification and the necessity of publicly defending one's partisan cause against adversaries. Partisanship therefore fuels collective discussion and partisans are the agents of "trial by discussion" (Rosenblum, 2008, 7).

To summarize, LD does not seem to threaten partisanship merely by creating a level playing field between parties and interest groups, because the associational form that partisanship takes is less significant than its content or motivation. Thus, whether partisanship is expressed via interest groups or via parties is normatively irrelevant: "[...] partisanship as a practice does not always follow closely the contours of party membership: It will extend beyond the face-toface contacts of membership to a broader network of political activists seeking to advance largely the same goals, even in the absence of formal attachments." (White and Ypi, 2011, 382). The

\footnotetext{
${ }^{29}$ However, it remains unclear how comprehensive such a notion of the common good must be in order to qualify as legitimate or acceptable. In the case of niche parties, for example, this vision can be very limited, which complicates the task of differentiating parties from groups. I cannot resolve this issue here.
} 
size of the association or the number of issues on its electoral agenda should not be what distinguishes parties from groups, but rather the bona fide attempt to "persuade people of their stand on the great debate of contemporary [American] politics concerning the scope of the national government." (Muirhead, 2014, 264).

LD fosters a more pluralistic partisanship conveyed by new, non-party actors. From this, it does not follow that all interest groups will become carriers of partisanship under LD, nor is it clear why interest groups would attempt to articulate a comprehensive vision of the public good. My analysis does, however, suggest that much of the traditional differences between parties and interest groups might result from an adaptational strategy, in which different behaviors and purposes result from the opportunities given by the political system. By opening up the system and changing its rules, LD might alter the behaviors of parties and interest groups, thus forcing us to adapt our understanding of them.

\section{Independent and Partisan Proxies}

An attack on the concept of independence is the flip side Rosenblum's defense of parties. In her eyes, the independent politician is faithless and detached, consciously disavowing partisanship (Rosenblum, 2008, 327). Her core argument is that independence (particularly, the progressive, American model of independence) is morally weightless and an inappropriate democratic ideal. Their refusal of partisan identity is an admission of detachment from society, yet independents "lack the drama of radical individualism with its global rejection of association and membership-Thoreau's alienation from civil society and revulsion at the thought of joining." (Rosenblum, 2008 , 351) They simply refuse to act politically alongside others, using independence as "a mask for political vacillation, weakness, inconsistency of temperament or self-interest." (Rosenblum, 2008, 349) Nor are independents necessarily impartial or neutral. In fact, their rejection of any partisan identity makes one wonder whether they are not simply pursuing self-interest or some hidden, sectarian goal. If partisanship is the engine that drives citizens to exercise collective political agency and a source of the democratic ethos (White and Ypi, 2010), its explicit disavowal makes independents suspicious figures at best.

The puzzle remains of whether or not LD has the inexorable tendency to promote an individualist politics based on the personalities of nonpartisan proxies. Do gyroscopic proxies not resemble independents? I do not believe so, since proxies are more likely to have a collective, partisan nature.

A non-partisan or independent proxy is someone who decides to run without any affiliation to an existing party (or interest group), exercising his or her own sole judgment about the common good and free from all partisan influence. This pure independent is a zealous and romantic intellectual opponent, a self-styled impartial moderator with great moral and political integrity. While this might sound like the ideal of the gyroscopic proxy, acting out of intrinsic conviction and indifferent to (re)election or power, this is not the case. An 'independent proxy' might be supported by many voters, but he or she nonetheless stands alone like an atom, unwilling to make any "good faith effort to stand with a group striving for democratic legitimacy" (Muirhead, 2014, 89). By contrast, commitment is fundamental to partisanship, which possesses normative value precisely because the passionate commitment to a partisan cause, coupled with tight interpersonal networks, is known to promote political knowledge and participation (Mutz, 2006, 3, Ch. 5). Earlier, I defined the gyroscopic proxy as a public-spirited representative who is intrinsically committed to his or her constituents' objectives. I now argue that this commitment to a common cause is responsible for the natural affinity between gyroscopic proxies and partisanship and that-since the notion of partisanship as a social identity entails the inescapable necessity and will to act with others-it promotes a sense of community or even friendship (Efthymiou, 2018, 196). Moreover, I also argue that proxies are compatible with partisanship because the proxy-voter relationship in $\mathrm{LD}$ is trust-based, comprising the alignment of objectives together with sympathy and likeness. In addition to being a possible member of a partisan organization, each proxy is also a potential carrier of partisanship, who stands for "a body of men united, for promoting by their joint endeavors the national interest, upon some particular principle in which they are all agreed." (Edmund Burke, cited in White, 2006, 2).

That said, LD tends to promote a multi-party system characterized by comparatively high levels of fragmentation. Parties-understood as carriers of partisanship, whether traditional parties, interest groups, or individual proxies-could proliferate without major hurdles in LD, thanks to a series of features, such as the absence of competition for seats and the possibility to selectively engage in political representation depending on the issue. A major challenge for parties and similar partisan organizations would be to ensure the unity of their elected members in the face of such a fragmented, volatile context. Whether commitment and intrinsic motivation would suffice for partisan proxies to construct highly cohesive agglomerates of like-minded individuals is questionable. In the absence of party lists, which are entirely open in $\mathrm{LD}$, proxies would be able to campaign for votes and build their own individual constituencies without the party label, giving them more freedom for open dissent. If some members' opinions begin to diverge in a way that threatens party unity, they can simply leave the party (taking their delegations) and become independent proxies. In a context where the party leadership cannot select top candidates, steer members' career paths, control the levers of political influence, or, more generally, punish 'rebels,' the importance of building a solid "record of loyalty" toward one's own party decreases (Kam, 2014, 14). Overall, there might be a trade-off between gyroscopic proxies and party discipline, raising the question of how to guarantee some cohesion and loyalty among party members. This, in turn, raises the urgent, but unanswered question of how the legislative assembly might work in such a volatile and fragmented context. This is, however, largely an empirical matter connected to the broader institutional set-up, which deserves more attention in future research (Kam, 2014).

\section{CONCLUSION}

This article started by asking whether LD dilutes the concept of political representation, by understanding it in purely Pitkinean 
formalistic and descriptive terms. Proxies in LD are representative in a formalistic sense, because they are elected by voluntary delegation and held accountable by instant recall. Moreover, both the proxies and the liquid legislature are descriptively representative, thanks to proxy voting, which ensures perfectly proportional representation, as well as to other features, such as the freely chosen proximity basis and area-specific delegations. This raises the question of whether there is a more substantive way of conceptualizing political representation under LD: Is LD compatible with a highquality, democratic understanding of representation? The answer to this question is a provisional yes, on the basis of an analysis of two gaps in the literature on political representation in LD.

First, the article disentangled the substantive view of representation in the proxy-voter relationship, arguing that $\mathrm{LD}$ is compatible with a selection model of representation, in which proxies are characterized as gyroscopic representatives. This approach has several implications: 1) the centrality of aligned objectives and intrinsic motivations explain how LD strikes a balance in the mandate-independence tradeoff; 2) resemblance and the sympathy of ideals give LD a clear anti-elitist slant; 3 ) the focus on issue control places deliberation center stage, giving LD a constructivist tendency. Second, the paper examined the function of parties in LD and reached the following conclusions: Even though LD puts parties and interest groups on a level playing field, 1) it challenges but does not necessarily eliminate parties $q u a$ organizations and 2) it expands the range of possible carriers of partisanship. Moreover, 3) gyroscopic proxies have more affinity with partisanship than with independence, because they are public-spirited, intrinsically motivated, and committed to a cause.

This article also pointed to a series of difficulties to be addressed by future research, for example: 1) the unclear impact of instant recall on the behavior of proxies; 2) the destabilizing effect of interest groups on governability; 3 ) the consequences of a functional view of representation and the resulting tendency toward a pluralist-corporatist theory of democracy; 4) the effect of LD on party discipline, partisan fragmentation, coordination, and policy coherence; 5) the great expectations and burdens placed on citizens to cultivate a deep, discursive relationship with their proxies, as well as to understand the complex, liquid system; 6) the uncertain repercussions of LD on parliamentary activity within the volatile legislative assembly and, most problematically, the potential loss of a stable, visible parliament as the supreme democratic institution. Overall, the article has highlighted the need to combine this theoretical framework with empirical insights, since much rests on the successful institutionalization of LD.

To conclude, this article is an indirect attempt to test the democratic credentials of LD. It has shown that the notion of political representation in LD is ensconced in thick concepts, since it embodies commitment, promotes intrinsic motivation, presupposes the alignment of objectives, fosters sympathy and trust, and enables dialogue. This conclusion goes a step beyond the literature, which has already anticipated LD's capacity to create a close bond between voters and proxies, along with its potential to foster expertize and collective intelligence. Clearly, the representation outlined in this article is quite demanding for both the representatives and the represented. From the proxies, it requires compliance with a certain ethics of representation, as well as of partisanship. In the represented, it proposes to cultivate the capacity for democratic citizenship, aiming at an ideal of active and vigilant citizenship capable of judgment and action. As such, LD presupposes a significantly more complex, mature, and dynamic relationship between representatives and represented, in which the judgments and activities of both parts are relevant and decisive. This, I would argue, is a framework capable of turning LD into an instrument for the "establishment of meaningful practices of self-government" in the twenty-first century (Castiglione and Pollak, 2018, 31).

\section{DATA AVAILABILITY STATEMENT}

The original contributions presented in the study are included in the article, further inquiries can be directed to the corresponding author.

\section{AUTHOR CONTRIBUTIONS}

$\mathrm{CV}$ is the sole author of this article.

\section{FUNDING}

This article is part of a cumulative dissertation funded by the Swiss National Science Foundation. Grant number of the $\mathrm{PhD}$ project: 191719 (see also: http://p3.snf.ch/project-191719).

\section{ACKNOWLEDGMENTS}

I would like to express my gratitude to Pierre-Etienne Vandamme for inviting me to contribute to this special issue, as well as for providing feedback during the early stages. I am also grateful to my supervisors, Francis Cheneval and Joseph Lacey, for their continued support in polishing and steering the manuscript in the right direction. My gratitude extends to my colleagues in the Doctoral Program Democracy Studies and at the Chair of Political Philosophy at the University of Zurich for their numerous questions and helpful comments -in particular, many thanks are due to Sara Amighetti and Olivier Ruchet for astutely pinpointing the main weaknesses of the manuscript and for providing constructive recommendations. Finally, I would like to acknowledge the work of the reviewers for their rigorous and professional feedback: their thoughtful guidance helped me improve my arguments substantially. The research and publication costs were generously financed by the Swiss National Science Foundation. The English-language editing was done by Chad Jorgenson (Better English). 


\section{REFERENCES}

Alger, D. (2006). Voting by proxy. Public Choice 126, 1-26. doi:10.1007/s11127006-3059-1

Barber, B. R. (2014). Participatory democracy. Encyclopedia Polit. Thought [Epub ahead of print]. doi:10.1002/9781118474396

Behrens, J., Kistner, A., Nitsche, A., and Swierczek, B. (2020). Liquid feedback. Available at: https://liquidfeedback.org (Accessed November 10, 2020).

Blum, C., and Zuber, C. I. (2016). Liquid democracy: potentials, problems, and perspectives. J. Polit. Philos. 24, 162-182. doi:10.1111/jopp.12065

Brownlee, K., and Jenkins, D. (2019). Freedom of association. Stanford encyclopedia of philosophy. Available at: https://plato.stanford.edu/entries/ freedom-association/ (Accessed August 5, 2020).

Castiglione, D., and Pollak, J. (2018). Creating political presence - the new politics of democratic representation. Chicago, lllinois: University Of Chicago Press.

Chapman, E. B. (2020). New challenges for a normative theory of parties and partisanship. Representation [Epub ahead of print]. doi:10.1080/00344893.2020.1738539

Coleman, S. (1995). Dynamics in the fragmentation of political party systems. Qual. Quantity 29, 141-155. doi:10.1007/BF01101895

Couperus, S. (2019). Democracy not lost? Functional democracy as a panacea for crisis in interwar Europe. Eur. J. Leg. Stud. 49, 252-266. doi:10.1177/2F0047244119859166

Efthymiou, D. E. (2018). The normative value of partisanship: when and why partisanship matters. Polit. Stud 66, 192-208. doi:10.1177/0032321717707401

Epstein, L. D. (1986). Political parties in the American mold. Madison, Wisconsin: University of Wisconsin Press.

Ford, B. (2002). Delegative democracy. Available at: https://bford.info/deleg/deleg. pdf (Accessed August 5, 2020).

Fossum, J. E. (2018). "Political parties and conflict handling," in Creating political presence - the new politics of democratic representation. Editors D. Castiglione and J. Pollak (Chicago, United Kingdom: University Of Chicago Press), 86-109.

Goodin, R. E. (2008). "The place of parties,"in Innovating Democracy. Editor R. E. Goodin (oxfard, England: Oxford University Press), 1-20.

Green-Armytage, J. (2015). Direct voting and proxy voting. Const. Polit. Econ. 26, 190-220. doi:10.1007/2Fs10602-014-9176-9

Hardt, S., and Lopes, L. C. R. (2016). Google votes: a liquid democracy experiment on a corporate social network: Tech. Discl. Commons. . Available at: https:// www.tdcommons.org/dpubs_series/79.

Hay, C. (2011). "Political ontology," in The Oxford handbook of political science. Editor R. E. Goodin (Oxford: Oxford University Press), 460-478.

Kam, C. (2014). "Party discipline," in The oxford handbook of legislative studies. Editors S. Martin, T. Saalfeld, and K. W. Strøm (Oxford: Oxford University Press), 399-417.

Lacey, J. (2017). Centripetal democracy: democratic legitimacy and political identity in Belgium, Switzerland, and the European Union. Oxford, England: Oxford University Press.

Landemore, H. (2020). Open democracy: reinventing popular rule for the twentyfirst century. Princeton, NJ: Princeton University Press.

Manin, B. (1996). Principes du gouvernement représentatif. Paris, France: Flammarion.

Mansbridge, J. (1999). Should blacks represent blacks and women represent women? A contingent “yes. J. Polit. 61, 628-657. doi:10.2307/2647821

Mansbridge, J. (2003). Rethinking representation. Am. Polit. Sci. Rev. 97, 515-528. doi:10.1017/S0003055403000856

Mansbridge, J. (2009). A “selection model" of political representation. J. Polit. Philos. 17, 369-398. doi:10.1111/j.1467-9760.2009.00337.x

Mansbridge, J. (2011). Clarifying the concept of representation. Am. Polit. Sci. Rev. 105, 621-630. doi:10.1017/S0003055411000189

Miller, J. C. (1969). A program for direct and proxy voting in the legislative process. Public Choice 7, 107-113. doi:10.1007/BF01718736

Muirhead, R. (2006). A defense of party spirit. Perspect. Polit. 4, 713-727. doi:10. $1017 /$ S1537592706060452

Muirhead, R. (2014). The promise of party in a polarized age. Cambridge, Massachusetts: Harvard University Press.

Mutz, D. C. (2006). Hearing the other side: deliberative versus participatory democracy. Cambridge, England: Cambridge University Press.

New York Times (1912). Government by proxy now: Oregon plan would present ideas of representative lawmaking. Available at: https://timesmachine.nytimes. com/timesmachine/1912/06/30/100586994.html?pageNumber=14 (Accessed August 5, 2020)
Paulin, A. A. (2019). "Controlling citizens or controlling the state? Apropos: the pirates \& co" in Smart city governance. Editor A. Alois (Amsterdam: Elsevier), $69-79$.

Philp, M. (2009). Delimiting democratic accountability. Polit. Stud. 57, 28-53. doi:10.1111/j.1467-9248.2008.00720.x

Pitkin, H. F. (2004). Representation and democracy: uneasy alliance. Scand. Pol. Studs. 27, 335-342. doi:10.1111/j.1467-9477.2004.00109.x

Pitkin, H. F. (1967). The concept of representation. Berkeley, California: University of California Press.

Plotke, D. (1997). Representation is democracy. Constellations 4, 19-34. doi:10. $1111 / 1467-8675.00033$

Przeworski, A. (1999). "Minimalist conception of democracy: a defense," in Democracy's value. Editors I. Shapiro and C. Hacker-Cordón (Cambridge, England: Cambridge University Press), 23-55.

Rehfeld, A. (2018). On representing: on representing. J. Polit. Philos. 26, 216-239. doi:10.1111/jopp.12137

Rehfeld, A. (2009). Representation rethought: on trustees, delegates, and gyroscopes in the study of political representation and democracy. Am. Polit. Sci. Rev. 103, 214-230. doi:10.1017/S0003055409090261

Rehfeld, A. (2006). Towards a general theory of political representation. J. Polit. 68, 1-21. doi:10.1111/j.1468-2508.2006.00365.x

Rosenblum, N. L. (2008). On the side of the angels: an appreciation of parties and partisanship. Princeton, NJ: Princeton University Press.

Runciman, D. (2007). The paradox of political representation. J. Polit. Philos. 15, 93-114. doi:10.1111/j.1467-9760.2007.00266.x

Sartori, G. (2005). Party types, organisation and functions. West. Eur. Polit. 28, 5-32. doi:10.1080/0140238042000334268

Saward, M. (2006). Representative Claim. Contemp. Polit. Theor. 5, 297-318. doi:10.1057/palgrave.cpt.9300234

Schattschneider, E. E. (1942). Party government: American government in action. Abingdon-on-Thames: Routledge.

Tullock, G. (1967). Toward a mathematics of politics. Ann Arbor: University of Michigan Press.

Urbinati, N. (2000). Representation as advocacy: a study of democratic deliberation. Polit. Theor. 28, 758-786. doi:10.1177/0090591700028006003

Urbinati, N. (2006). Representative democracy: principles and genealogy. Chicago, United States: University of Chicago Press.

Urbinati, N., and Warren, M. E. (2008). The concept of representation in contemporary democratic theory. Annu. Rev. Polit. Sci. 11, 387-412. doi:10. 1146/annurev.polisci.11.053006.190533

Valsangiacomo, C. (2020). Liquid democracy: defining a new concept in political theory.

Vandamme, P.-E. (2020). Can the recall improve electoral representation? Front. Polit. Sci. 2, 1-13. doi:10.3389/fpos.2020.00006

Warren, M. E. (2017). "How representation enables democratic citizenship," in In creating political presence - the new politics of democratic representation. Editors D. Castiglione and J. Pollak (Chicago,United States: University Of Chicago Press), 39-60.

Weale, A. P. (1981). Representation, individualism, and collectivism. Ethics 91, 457-465. doi:10.1086/292253?journalCode=et

White, J. K. (2006). "What is a political party?", in Handbook of party politics. Editors R. S. Katz and W. J. Crotty (London: SAGE Publications Ltd), 6-15.

White, J., and Ypi, L. (2011). On partisan political justification. Am. Polit. Sci. Rev. 105, 381-396. doi:10.1017/S0003055411000074

White, J., and Ypi, L. (2010). Rethinking the modern prince: partisanship and the democratic ethos. Polit. Stud 58, 809-828. doi:10.1111/j.1467-9248.2010.00837.x

Young, I. M. (1997). Deferring group representation. Nomos 39, 349-376. doi:10. $18574 / 9780814788851-015$

Conflict of Interest: The author declares that the research was conducted in the absence of any commercial or financial relationships that could be construed as a potential conflict of interest.

Copyright (c) 2021 Valsangiacomo. This is an open-access article distributed under the terms of the Creative Commons Attribution License (CC BY). The use, distribution or reproduction in other forums is permitted, provided the original author(s) and the copyright owner(s) are credited and that the original publication in this journal is cited, in accordance with accepted academic practice. No use, distribution or reproduction is permitted which does not comply with these terms. 